\title{
EFEITO DA ESCARIFICAÇÃO E DA TEMPERATURA NA GERMINAÇÃO DE SEMENTES DE Livistona rotundifolia (Lam.) Mart.
}

Fábio Alessandro Padilha Viana ${ }^{1}$, Kathia Fernandes Lopes Pivetta ${ }^{2}$, Lilian Gomes da Silva Rocha $^{3}$

${ }^{1}$ Professor Doutor em Agronomia - Produção e Tecnologia de Sementes, Faculdade de Agronomia e Medicina Veterinária (FAV), Universidade de Brasília (DF).

2 Professora Doutora em Agronomia, Departamento de Produção Vegetal, UNESP Campus de Jaboticabal (SP).

${ }^{3}$ Eng $^{\mathrm{a}}$. Florestal, Departamento de Engenharia Florestal, Universidade de Brasília (DF).

RESUMO: A Livistona rotundifolia (Lam.) Mart. é uma espécie da Família Arecaceae, nativa de países de Oceania, muito apropriada para cultivo em vasos e para ornamentação de parques e jardins. A propagação desta palmeira é feita por sementes, porém, há relatos de que a germinação é lenta e desuniforme e não há estudos sobre o comportamento germinativo desta espécie. Desta forma, o objetivo deste trabalho foi estudar o efeito da temperatura e da escarificação na germinação de sementes de $L$. rotundifolia. Foi utilizado o delineamento inteiramente casualizado, em esquema fatorial 2 x 4 (sementes escarificadas ou não, submetidas a germinação em condições não controladas de laboratório e as temperaturas de $30^{\circ} \mathrm{C}$ constante, e $20-30^{\circ} \mathrm{C}$ e $25-35^{\circ} \mathrm{C}$ alternadas, com fotoperíodo de 12 horas, com cinco repetições de 15 sementes, por tratamento. O material vegetal utilizado foi constituído por frutos coletados e despolpados, de uma planta matriz localizada na Faculdade de Ciências Agrárias e Veterinárias FCAV/UNESP, Campus de Jaboticabal (SP). Foram avaliados a porcentagem e o índice de velocidade de germinação. Não houve germinação nas condições de ambiente não controlado. A maior germinação dos diásporos de L. rotundifolia, foi obtida com diásporos escarificados mecanicamente, na temperatura alternada de $25-35^{\circ} \mathrm{C}$.

Palavras-chave: Palmeira. Dormência. Qualidade fisiológica.

\section{EFFECT OF SCARIFICATION AND TEMPERATURE ON GERMINATION OF Livistona rotundifolia (Lam.) Mart. SEEDS}

\begin{abstract}
Livistona rotundifolia (Lam.) Mart. is an Arecaceae Family specieS, native of Oceania countries, very appropriated for cultivation in containers and in the landscape. This palm tree is seed propagated, however, there are reports that germination is slow and not uniform and there are no studies about the germinative behavior of this spicies. Therefore, this work was carried out to study the temperature and scarification effect on germination of $L$ rotundifolia seeds. The used design was an entirely randomized, in a factorial scheme $2 \times 4$ (4 temperature conditions: constant controlled temperature of $30^{\circ} \mathrm{C}$, alternated controlled temperature of $20-30^{\circ} \mathrm{C}$ and $25-35^{\circ} \mathrm{C}$, with photoperiod of 12 hours, uncontrolled temperature conditions, and mechanical scarification: with and without), with
\end{abstract}

Cultura Agronômica, Ilha Solteira, v.25, n.1, p.65-70, 2016 
5 replicates of 15 seeds. The used vegetable material a lot of 600 fruits collected from one plant located at the Faculdade de Ciências Agrárias e Veterinárias - FCAV/UNESP, Jaboticabal, state of São Paulo, Brazil. The germination percentage and Speed Germination Index were evaluated. The variance analysis was accomplished in a factorial scheme $3 \times 2$ (temperatures of $30^{\circ} \mathrm{C}, 20-30^{\circ} \mathrm{C}$ and $25-35^{\circ} \mathrm{C}$ and mechanical scarification: with and without), because there was not germination at uncontrolled conditions, with average temperature of $20,5^{\circ} \mathrm{C}$. For diaspore germination of Livistona rotundifolia the best results were obtained with mechanically scarified diaspore, in alternated temperature of $25-35^{\circ} \mathrm{C}$.

Key words: Palm tree. Dormancy. Physiological quality.

\section{INTRODUÇÃO}

A maioria das espécies da Família Arecaceae é propagada sexuadamente. No entanto, este processo, freqüentemente, é dificultado, pois, de uma maneira geral, a germinação das sementes é lenta e desuniforme (MEEROW, 1991) e é influenciada por vários fatores como o grau de maturação, a presença ou não do pericarpo, o tempo entre a colheita e a semeadura, a dormência física, a temperatura do ambiente, o substrato, entre outros.

Odetola (1987), estudando a dormência, viabilidade e germinação de sementes de palmeiras ornamentais, concluiu que não existe dormência (fisiológica) em relação ao embrião, que se desenvolve continuamente após a maturação do fruto. No entanto, muitas espécies da família Arecaceae apresentam dormência (física) de sementes em graus variados, demandando tratamentos como embebição em água e em substâncias químicas reguladoras de crescimento, estratificação, escarificação química ou mecânica, ou mesmo, graus de exposição à luminosidade.

Da Luz et al. (2008), ao avaliarem a eficiência de diferentes tratamentos prégerminativos para acelerar e uniformizar a germinação das sementes de Rhapis excelsa (Thumberg) Henry ex. Rehder concluíram que para a germinação das sementes dessa palmeira a escarificação mecânica proporciona maior germinação do que as escarificações térmica e química, realizadas a partir da imersão em água quente e em ácido sulfúrico.

Há variação na indicação da faixa ideal para a germinação de sementes de diferentes espécies de palmeiras. Generalizando, para várias espécies, os melhores resultados podem ser obtidos entre 30 e $35^{\circ} \mathrm{C}$ (MEEROW, 1991), 25 e $35^{\circ} \mathrm{C}$ (BROSCHAT, 1994) e 24 e $28^{\circ} \mathrm{C}$ (LORENZI et al., 1996).

O objetivo do presente trabalho foi determinar o efeito da temperatura e da escarificação mecânica na germinação de sementes de Livistona rotundifolia (Lam.) Mart., espécie da Família Arecaceae. 


\section{MATERIAL E MÉTODOS}

O trabalho foi conduzido no Laboratório de Análise de Sementes do Departamento de Produção Vegetal da Faculdade de Ciências Agrárias e Veterinárias, FCAV/UNESP, Campus de Jaboticabal, SP.

O delineamento experimental utilizado foi inteiramente casualizado, em esquema fatorial $2 \times 4$ (sementes escarificadas ou não, submetidas a germinação em condições não controladas de laboratório e as temperaturas de $30^{\circ} \mathrm{C}$ constante, e $20-30^{\circ} \mathrm{C}$ e $25-35^{\circ} \mathrm{C}$ alternadas, com fotoperíodo de 12 horas, com cinco repetições de 15 sementes, por tratamento.

Os frutos foram coletados no dia 10 de julho de 2001, de uma planta matriz localizada no Campus da FCAV / UNESP, sendo submetidos à despolpa manual após terem sido colocados em água, em temperatura ambiente durante $24 \mathrm{hs}$, para facilitar a remoção do pericarpo (polpa). Os diásporos (semente com o endocarpo aderido), após serem despolpados, permaneceram em água por $12 \mathrm{hs}$, para hidratação do endocarpo. Decorrido esse período, o lote inicial foi separado em dois sub-lotes de 300 diásporos que sofreram dois tipos de tratamento.

No primeiro sub-lote, os diásporos foram submetidos a escarificação mecânica com auxílio de um esmeril elétrico, retirando-se pequena porção do endocarpo, expondo o endosperma, com intuito de acelerar a embebição e promover germinação mais rápida. No outro sub-lote, os diásporos permaneceram intactos. Após estes tratamentos, os diásporos foram submetidos a uma desinfecção por meio de imersão em hipoclorito de sódio, na concentração de $5 \%$, por cinco minutos, sendo posteriormente lavados em água corrente por 10 minutos.

Feita a desinfeção, os diásporos foram colocados para germinar em caixas de plástico (tipo gerbox) preenchidas com esfagno. Cada caixa correspondia a uma parcela.

De acordo com o tratamento, os diásporos foram colocados para germinar em germinadores regulados com temperatura constante $\left(30^{\circ} \mathrm{C}\right)$, temperaturas alternadas $(20$ $30^{\circ} \mathrm{C} ; 25-35^{\circ} \mathrm{C}$ ) com fotoperíodo de $12 \mathrm{~h}$ e condições não controladas de ambiente de laboratório que, nos meses de julho, agosto e setembro de 2001, atingiram, em média, 18,8, 21,5 e $21,3^{\circ} \mathrm{C}$, respectivamente (dados fornecidos pela Estação Agroclimatológica do Departamento de Ciências Exatas da FCAV/UNESP).

A contagem da germinação foi realizada diariamente, a partir do dia 29/7/2001 até o dia 5/9/2001, para se determinar a porcentagem de germinação (BRASIL, 1992) e o índice de velocidade de germinação (IVG), calculado por meio da fórmula proposta por Maguire (1962). Os dados de porcentagem de germinação foram transformados em arc sen $\sqrt{x / 100}$.

Os dados foram analisados em esquema fatorial 3 x 2, pois não houve germinação quando as sementes foram colocadas para germinar em condições não controladas de ambiente de laboratório, independente destas terem sido escarificadas ou não.

Cultura Agronômica, Ilha Solteira, v.25, n.1, p.65-70, 2016 


\section{RESULTADOS E DISCUSSÃO}

A temperatura foi fator limitante para a germinação, pois, quando os diásporos foram colocados em ambiente não controlado, com temperatura de $20,5^{\circ} \mathrm{C}$, não houve germinação.

Os resultados de porcentagem de germinação e índice de velocidade de germinação (IVG) são apresentados na Tabela 1.

Tabela 1. Quadrados médios e médias obtidas para porcentagem de germinação e Índice de Velocidade de Germinação (IVG) de diásporos de Livistona rotundifolia submetidos a três temperaturas com e sem escarificação. Jaboticabal, SP, 2003.

\begin{tabular}{|c|c|c|c|}
\hline Causa da Variação & GL & Germinação (\%) & IVG \\
\hline Temperatura (T) & 2 & $6765,65 * *$ & $0,3644 * *$ \\
\hline Escarificação (E) & 1 & $2739,51 * *$ & $0,2279 * *$ \\
\hline $\mathbf{T} \times \mathbf{E}$ & 2 & 134,80 ns & $0,754 *$ \\
\hline Resíduo & 24 & 231,1 & 0,192 \\
\hline $\mathrm{CV}(\%)$ & & 27,25 & 40,02 \\
\hline Médias $^{1 /}$ & & Germinação (\%) $)^{1 /}$ & IVG \\
\hline $\mathrm{T} 30^{\circ} \mathrm{C}$ & & $48,7 \mathrm{~B}$ & --- \\
\hline T $20-30{ }^{\circ} \mathrm{C}$ & & $32,7 \mathrm{C}$ & --- \\
\hline T $25-35^{\circ} \mathrm{C}$ & & $64,2 \mathrm{~A}$ & --- \\
\hline Escarificadas & & $53,9 \mathrm{~A}$ & --- \\
\hline Não Escarificadas & & $42,8 \mathrm{~B}$ & --- \\
\hline Médias $^{2 /}$ & & Germinação (\%) ${ }^{2 /}$ & IVG \\
\hline $\mathrm{T} 30^{\circ} \mathrm{C}$ & & $56,6 \mathrm{~B}$ & --- \\
\hline T $20-30^{\circ} \mathrm{C}$ & & $29,3 \mathrm{C}$ & --- \\
\hline T $25-35^{\circ} \mathrm{C}$ & & $81,3 \mathrm{~A}$ & --- \\
\hline Escarificadas & & $65,3 \mathrm{~A}$ & --- \\
\hline Não Escarificadas & & $46,2 \mathrm{~B}$ & --- \\
\hline $\mathrm{T} 30^{\circ} \mathrm{C}$ & & --- & --- \\
\hline Escarificadas & & --- & $0,48 \mathrm{~A}$ \\
\hline Não Escarificadas & & --- & $0,40 \mathrm{~A}$ \\
\hline T $20-30^{\circ} \mathrm{C}$ & & --- & --- \\
\hline Escarificadas & & --- & $0,15 \mathrm{~A}$ \\
\hline Não Escarificadas & & --- & $0,09 \mathrm{~A}$ \\
\hline T $25-35^{\circ} \mathrm{C}$ & & --- & --- \\
\hline Escarificadas & & --- & $0,65 \mathrm{~A}$ \\
\hline Não Escarificadas & & --- & $0,27 \mathrm{~B}$ \\
\hline
\end{tabular}

${ }^{1}$ Dados transformados em arc sen $\sqrt{x / 100}$.

${ }^{2}$ Dados não transformados.

Médias seguidas da mesma letra na coluna não diferem entre si pelo Teste de Tukey a 5\% de probabilidade.

Tanto a temperatura como a escarificação promoveram efeito significativo na porcentagem de germinação, bem como no IVG. Para porcentagem de germinação, não 
houve efeito significativo de interação entre temperatura e escarificação. Entre as temperaturas testadas, a alternada de $25-35^{\circ} \mathrm{C}$ promoveu germinação significativamente superior às demais (Tabela 1).

Este resultado está de acordo com a temperatura recomendada por Broschat (1994) para várias espécies de palmeiras. Já Lorenzi et al. (1996) relataram que, para a germinação de diásporos de várias espécies de palmeiras, são consideradas favoráveis temperaturas entre 24 e $28^{\circ} \mathrm{C}$ e, para Meerow (1991), temperaturas entre 20 e $40^{\circ} \mathrm{C}$ são aceitáveis, ocorrendo melhores resultados entre 30 e $35^{\circ} \mathrm{C}$, para a maior parte das espécies. Outros autores, no entanto, trabalhando com a germinação de diásporos de diferentes espécies de palmeiras, encontraram resultados distintos, como $30-35^{\circ} \mathrm{C}$ para Dypsis lutescens (BROSCHAT; DONSELMAN, 1986), $25^{\circ} \mathrm{C}$ para Rhapis excelsa (AGUIAR et al., 2001), 25 e $30^{\circ} \mathrm{C}$ para Phoenix roebelenii (IOSSI et al., 2003).

Isso mostra que, embora a maioria das palmeiras seja de origem tropical, cujos diásporos geralmente germinam, de forma natural, em temperaturas mais elevadas, não se pode generalizar a recomendação, havendo, inclusive, diferenças entre temperatura constante ou alternada. Para cada espécie, é necessário um estudo prévio para determinar a temperatura que proporciona o melhor resultado, pois se observa (Tabela 1) que uma pequena alteração na temperatura, pode reduzir consideravelmente a porcentagem de germinação, como verificado para as temperaturas $25-35^{\circ} \mathrm{C}$ e $20-30^{\circ} \mathrm{C}$ ).

Quanto ao efeito da escarificação, este também foi significativo, pois os diásporos escarificados tiveram maior porcentagem de germinação que os intactos, resultado que concorda com os obtidos por Nagao et al. (1980), em que a germinação dos diásporos de Archontophoenix alexandrae que tiveram o tegumento escarificado mecanicamente foi superior.

$\mathrm{O}$ efeito da interação entre as temperaturas e a escarificação foi estatisticamente significativo somente para o IVG, observando-se que na temperatura alternada de $25-35^{\circ} \mathrm{C}$, os diásporos escarificados germinaram em menor tempo em comparação com os intactos na mesma temperatura.

\section{CONCLUSÃO}

Para melhores resultados em termos de germinação, diásporos de Livistona rotundifolia devem ser escarificados mecanicamente e postos a germinar sob temperatura alternada de $25-35^{\circ} \mathrm{C}$.

\section{REFERÊNCIAS BIBLIOGRÁFICAS}

AGUIAR, F. F. A.; BARBEDO, C. J.; BILIA, D. A. C.; KANASHIRO, S.; TAVARES, A. R. Germinação de sementes de palmeira ráfia: efeito do estágio de maturação dos frutos, da temperatura, da luz e do substrato. In: CONGRESSO BRASILEIRO DE FLORICULTURA

Cultura Agronômica, Ilha Solteira, v.25, n.1, p.65-70, 2016 
E PLANTAS ORNAMENTAIS, 13, 2001. São Paulo. Resumos... São Paulo: Sociedade Brasileira de Floricultura e Plantas Ornamentais, 2001. p. 71.

BRASIL. Ministério da Agricultura e da Reforma Agrária. Regras para Análise de Sementes. Brasília: SNDA/DNDV/CLAV, 1992. 365 p.

BROSCHAT, T. K. Palm seed propagation. Acta Horticulturae, Wageningen, v. 360, p.141-147, 1994.

BROSCHAT, T. K.; DONSELMAN, H. Factors affecting storage and germination of Chrysalidocarpus lutescens seeds. Journal American Society for Horticultural Science, Alexandria, v. 111, n. 6, p. 872-877, 1986.

DA LUZ, P. B.; TAVARES, A. R.; OLIVEIRA PAIVA, P. D.; AGUIAR, F. F. A.; KANASHIRO, S. Germinação de sementes de palmeira-ráfia: efeito de tratamentos prégerminativos. Revista Árvore, Viçosa, v. 32, n. 5, p.793-798, 2008.

IOSSI, E.; SADER, R.; PIVETTA, K. F. L.; BARBOSA, J. C. Substrates and temperatures on germination of Phoenix roebelenii 'Brien. Revista Brasileira de Sementes, Brasília, v. 25, n. 2, p.63-69, 2003.

LORENZI, H.; SOUZA, H. M.; MEDEIROS-COSTA, J.T.; CERQUEIRA, L.S.C.; VON BEHR, N. Palmeiras no Brasil: nativas e exóticas. Nova Odessa: Plantarum, 1996. 241 p.

MAGUIRE, J. D. Speed of germination aid in selection and evaluation of seedling emergence and vigor. Crop Science, Madison, v. 2, n. 1, p.176-177, 1962.

MEEROW, A. W. Palm seed germination. Florida: Cooperative Extension Service, 1991. 10 p. (Bulletin, 274).

NAGAO, M.A.; KANEGAWA, W.; SAKAI, S. Accelerating palm seed germination with gibberellic acid, scarification and bottom heat. Hortscience, Alexandria, v. 15, n. 2, p.200$201,1980$.

ODETOLA, J.A. Studies on seed dormancy, viability and germination in ornamental palms. Principes, Lawrence, v. 31, n. 1, p.24-31, 1987. 